\title{
A ciência e o cristianismo: uma análise crítica da aplicação da cosmovisão cristã na ciência através da polêmica entre Teoria da Evolução e o Design Inteligente
}

\begin{abstract}
Science and Christianity: a critical analysis of the application of the Christian cosmovision to science through the polemic between the Theory of Evolution and the Intelligent Design
\end{abstract}

\section{Francisco das Chagas Nascimento Sousa Tourinho*}

\begin{abstract}
Resumo
Nesse artigo defenderemos não haver uma guerra real entre ciência e a religião cristã. Defenderemos que deve haver uma complementação entre ciência e religião, não devendo haver uma compartimentalização, sendo os dois campos de conhecimento que nos propiciam elementos importantes para chegarmos a única verdade de Deus. O artigo sugere uma conduta do cristão diante dos avanços científicos e como relacioná-las com as verdades eternas das Escrituras Sagradas. Para isso escolhemos como caso esquemático a polêmica entre Teoria da Evolução e Design Inteligente, que é uma polêmica atual. Através da análise mostramos um caso prático de como deve ser o posicionamento cristão diante de dados científicos que podem ser contraditórios e suas implicações para uma cosmovisão cristã. Por fim, concluímos que a ciência e a teologia devem estar unidas para promover o bem para a humanidade, e que assim como a ciência pode ajudar o teólogo, a teologia pode contribuir com o cientista, pois nenhum dos campos são completos em si.
\end{abstract}

\section{Palavras-chave}

Ciência. Teologia. Evolução. Design Inteligente.

\begin{abstract}
In this paper, we will defend there is no real war between science and the christian religion. We defend that must have a complementation between science and religion, instead of a compartimentalization, as these two knowledge fields propitiate us important elements to come up with an unique truth about God. The paper suggests a behavior from the christian, in the face of cientific advances and how to relate them with the eternal truths from de Holy Scriptures. In order to do that, we chose as a schematic
\end{abstract}

[Texto recebido em março de 2017 e aceito em junho de 2017, com base na avaliação cega por pares realizada por pareceristas ad hoc]

Membro da Primeira Igreja Batista de Dourados. Licenciado em Educação Física (Universidade Estadual do Piauí - UESPI). Bacharel em Teologia (Faculdade Teológica de Imperatriz - FATEIMP). PósGraduando em Psicopedagogia (Universidade Católica Dom Bosco - UCDB). Mestrando em Estudos Teológicos pelo Seminário Internacional de Miami (MINTS). E-mail: tourinho10@hotmail.com 
case the controversy between Evolution Theory and Intelligent Design, which is a current debate. Through analysis we show a practical case about how the christian statements should be according the contradictory scientific data and their implications to the christian worldview. At last, we conclude that science and theology must be together to promote the good for the mankind, and as well as the science can help the theologian, the theology can contribute with the scientist, because neither of the fields is complete in itself.

\section{Keywords}

Science. Theology. Evolution. Intelligent Design.

\section{Introdução}

Desde o declínio do período medieval e o surgimento da ciência moderna, juntamente com as novas ideias do iluminismo e uma volta ao antropocentrismo, que é instalada uma guerra entre a ciência e a religião. No entanto, demonstraremos nesse artigo que essa guerra é desnecessária. Como o cristão deve se portar diante dos avanços científicos? O que a ciência pode dizer à teologia? O que a teologia tem a dizer à ciência? São perguntas que tentaremos responder nesse artigo, sugerindo uma conduta que o cristão poderá adotar diante da ciência.

Para isso, faremos uma abordagem sucinta da história da ciência e da pretensa luta contra a religião, desde a origem da ciência moderna, com uma breve referência ao conflito medieval entre o realismo e nominalismo, passando por autores como Guilherme de Occan, Roger Bacon e Tomás de Aquino. Em ato contínuo, trabalharemos os conceitos de Teoria da Evolução e do Design Inteligente, suas implicações éticas e como relacionálas com a teologia, demonstraremos que certos tipos de posicionamentos teológicos diante da ciência e certos posicionamentos científicos diante da teologia podem ser prejudiciais ao relacionamento entre essas duas formas de ver o mundo, que poderão ser poderosas armas, se bem usadas, para promover o bem da humanidade.

\section{A ciência e a religião estão em guerra?}

Há uma ilusão criada durante a Idade Moderna de que há uma disputa entre ciência e religião, "isso se deve à intenção da ciência se tornar independente da fé". ${ }^{1}$ No entanto, esse conflito nem sempre existiu. Segundo o distinto historiador da ciência Stanley Jaki, ${ }^{2}$ foi dentro o cristianismo que a ciência moderna encontrou um campo fértil, pois foi a fé em um criador racional que propiciou os alicerces para o desenvolvimento da ciência. Outro distinto historiador, Earle E. Cairns, também diz que:

1 RAMSEY, R. B. Integridad intelectual: el desarrollo de una cosmovisión cristiana. [s.1.]: Clie, [s.d.].

2 Padre de ordem beneditina com um doutorado em teologia e outro doutorado em física e distinto historiador da ciência. Um resumo da obra, onde ele defende o ponto de vista citado nesse artigo, pode ser lido nesse link: <https://www.surrey.ac.uk/ati/ibc/files/Science\&Creation.pdf>. Acesso em: 12 fev. 2017. 
A expansão do movimento universitário, que começou no século XII, deu um lugar para o novo movimento intelectual; tanto é que nas universidades logo centralizaram seus currículos em torno da teologia e pela ajuda da lógica com a da razão. ${ }^{3}$

O próprio surgimento das Universidades, dentro do seio da Igreja Cristã, é uma prova de que a busca pelo conhecimento não era de modo algum algo separado da fé. $\mathrm{O}$ professor Cairns continua explicando que Roger Bacon (1214-1292) teria sido "quem colocou os fundamentos da ciência experimental", ${ }^{4}$ também com Guilherme de Occam (1280-1349), e mais tardiamente com Francis Bacon (1561-1626). Esse último é considerado o Pai da ciência moderna.

Como vemos, a ciência moderna surgiu dentro dos seios da Igreja, no entanto, ao mesmo tempo que a ciência surgiu dentro Igreja, sua semente ateísta também, tudo foi uma questão de pressuposto, de um modo de investigação do mundo dentro de duas principais correntes filosóficas da época - o realismo ${ }^{5}$ moderado, defendido por São Tomás de Aquino, e o nominalismo, defendido por Guilherme de Occam. No realismo moderado, as coisas existiam primeiro na mente de Deus e só depois na realidade, já para o nominalismo, " as verdades ou ideias gerais não têm existência objetiva fora da mente; ao contrário elas são apenas ideias subjetivas formadas pela mente como resultado da observação de coisas particulares". ${ }^{6}$ Os realistas moderados pregavam que a verdade era uma só: “Tomás procurou harmonizar as áreas da fé e da razão numa totalidade de verdade" ${ }^{7}$ Já os nominalistas pregavam que havia uma área de conhecimento da verdade científica e outro de verdades teológicas. Em resumo Cairns, diz:

A doutrina tomista de que a razão precede a revelação como instrumento de conhecimento e que é completada pela revelação descambava para o perigo de que a verdade conhecida por esses dois métodos poderia se separar em duas esferas, a secular e a sagrada. Essa separação se evidencia no pensamento dos nominalistas que criam que há um campo da verdade científica e um outro da verdade teológica, em vez de entender que os dois são partes de um todo maior unificado em Deus como Criador. O nominalismo criou um novo interesse no homem, uma vez que, segundo ele, o indivíduo era mais real do que a instituição. Esse interesse fomentou

3 CAIRNS, E. E. O cristianismo através dos séculos: uma história da igreja cristã. São Paulo: Vida Nova, 1995. p. 188.

4 CAIRNS, 1995, p. 193.

5 O realismo pode se dividir em duas correntes, o radical e o moderado. O radical foi defendido por Platão e na Idade Média foi defendido por Erígena. Essa filosofia ensina que existe uma realidade exterior que ele chama de mundo das Ideias ou Universal, um mundo que não pode ser percebido pelos sentidos e tudo no mundo material em que nós vivemos, que seria o particular, é apenas um reflexo imperfeito desse mundo dos Universais ou das Ideias. Na Idade Média, foi adotado um realismo moderado, cujo defensor era Aristóteles originalmente, mas na Idade Média iniciou com Boécio, e mais tardiamente na escolástica com Anselmo e principalmente com Tomás de Aquino.

6 CAIRNS, 1995, p. 193.

7 CAIRNS, 1998, p. 191. 
muito do materialismo da Renascença, quando as pessoas começaram a pensar no homem como autônomo e a exaltar o método experimental como o principal caminho para a verdade. Outros que seguiram ideias nominalistas encaminharam para o misticismo como forma pela qual o indivíduo poderia ir diretamente à presença de Deus. ${ }^{8}$

Segundo Stanley Jaki, “Aquino é notável por sua falta de apreço pela investigação experimental, mas esta não era uma característica particular de seus contemporâneos. Seu mestre, Albertus Magnus (1200-1280), foi um experimentador notável". ${ }^{9}$ Os nominalistas deram muita ênfase à experimentação, e foram eles os pais da ciência moderna. Na filosofia nominalista, existiam dois campos de verdade, a teológica e a científica, criando assim uma dicotomia entre o secular e o sagrado, razão e fé, pois as verdades teológicas deveriam ser aceitas pela fé, enquanto as verdades científicas deveriam estar sujeitas a experimentos para evidenciar suas verdades. A rejeição dos absolutos pregada pelos nominalistas como Roscelin e Guilheme de Occam foi de onde surgiu a semente ateísta da ciência, de fato, a ciência já nasceu com um arcabouço pronto para qualquer mente tendenciosa poder descartar Deus.

Ainda assim, notem que em nenhuma das duas visões, nominalista e realista moderada, precisava-se negar a Deus para fazer ciência, então não há uma guerra de fato entre ciência e religião, nenhum grande cientista precisaria negar a Deus para fazer Ciência. Todos os pais da Ciência e os grandes inventores eram teístas e nunca precisaram ser ateus para serem cientistas, é o caso de Francis Bacon, pai do método científico, Isaac Newton, pai da física, Gregor Mendel, pai da genética, dentre uma infinidade de grandes cientistas que desenvolveram ciência muito boa sem jamais precisar tirar Deus dela, nem mesmo o polêmico Charles Darwin jamais chegou a negar a Deus, pelo contrário, usou teologia positiva para elaborar sua teoria. ${ }^{10}$ Então, na pior das hipóteses, a teologia e a ciência tratariam de áreas diferentes, a Teologia trataria das áreas dedicadas à ética, moral, aconselhamento espiritual, sentido da vida, enfim, das questões últimas do ser, enquanto a Ciência trataria de aspectos práticos que pudesse melhorar a vida do homem, como construção de tecnologia como computadores (o pai do computador, Charles Babbage, também era cristão), televisão, controles remotos, veículos automotivos etc. Ou seja, não há guerra entre ciência e religião em nenhuma das hipóteses, nem mesmo na pior delas. Essa ideia da guerra entre religião e ciência foi criada mais tardiamente, quando se lançou a ideia de que a Igreja Católica queria impedir o progresso da ciência para proteger seus dogmas religiosos, baseados principalmente nos polêmicos casos de Giordano Bruno e Galileu Galilei.

CAIRNS, 1995, p. 194.

9 JEYNES, C. Science and Creation: an abridgement of the book by Stanley Jaki. Abril 2002. p. 54. Disponível em: <https://www.surrey.ac.uk/ati/ibc/files/Science\&Creation.pdf>. Acesso em: 14 fev. 2017.

10 DILLEY, S. Charles Darwin's use of theology in the Origin of Species. British Journal for the History of Science, v. 45, mar. 2012. p. 29-56. Disponível em: <https://www.ncbi.nlm.nih.gov/pubmed/22702030>. Acesso em: 20 fev. 2017. 
Nos tempos da Reforma, os protestantes se esforçaram para fazer boa ciência e defender a ciência. Na teologia reformada, tudo deveria está debaixo do escrutínio das Escrituras. O posicionamento de João Calvino era:

Inumeráveis são, tanto no céu quanto na terra, as evidências que lhe atestam a mirífica sabedoria. Não apenas aquelas coisas mais recônditas, a cuja penetrante observação se destinam a astronomia, a medicina e toda a ciência natural, senão também aquelas que saltam à vista a qualquer um, ainda o mais inculto e ignorante, de sorte que nem mesmo podem abrir os olhos e já se veem forçados a ser-lhes testemunhas. ${ }^{11}$

Calvino também diz:

Entrementes, não hesitemos em colher piedoso deleite das obras de Deus manifestas e patentes neste formosíssimo teatro. Pois, como o dissemos em outro lugar, embora não seja a evidência primordial à fé, contudo na ordem da natureza esta é a primeira: para onde quer que volvamos os olhos em derredor, devemos ter em mente que todas as coisas que nossos olhos divisam são obras de Deus, e ao mesmo tempo devemos refletir, em piedosa consideração, a que fim foram por Deus criadas. ${ }^{12}$

Portanto, vemos claramente que o posicionamento reformado era o de refletir, em piedosa consideração, a que fim as coisas na natureza tinham sido criadas, numa referência clara ao estudo e à descoberta da finalidade de cada objeto na natureza. Isso não é outra coisa a não ser a ciência. Parece que os pressupostos metafísicos, como causa final e um agente criador no qual a criação era reflexo dele, faziam parte do modo como se fazia ciência.

\section{Estudo de caso: Teoria da Evolução vs. Teoria do Design Inteligente}

Atualmente existe uma briga entre os proponentes da Teoria da Evolução, que é aceita pela esmagadora maioria dos cientistas, e os proponentes da Teoria do Design Inteligente. Qual a relevância disso? A relevância é que quando se fala em origens, podemos ter implicações teológicas e filosóficas, as perguntas "de onde eu vim?", e "para onde vou?" são perguntas milenares e que ainda atormenta aqueles que têm um senso filosófico mais aguçado, e as duas propostas sobre as origens despertam essas implicações metafísicas. A partir de agora faremos uma análise dessas duas correntes e dentro dessa disputa, tentar fazer uma análise do proceder cristão para com a ciência.

11 CALVINO apud PORT JR, W. A relação entre João Calvino e o desenvolvimento das ciências modernas. Revista Teologia Brasileira, $2013 . \quad$ Disponível em: <http:/ / www.teologiabrasileira.com.br/teologiadet.asp?codigo=350>. Acesso em: 18 fev. 2017.

12 CALVINO apud PORTE JR, 2013. 
Teoria da Evolução: conceito

Teoria da Evolução é:

[...] em termos simples, é descendência com modificação. Essa definição engloba evolução em pequena escala (mudanças em frequência gênica em uma população de uma geração para a próxima) e evolução em larga escala (a progênie de espécies diferentes de um ancestral comum após muitas gerações). ${ }^{13}$

A Teoria da Evolução tem como carro chefe a ideia da Seleção Natural. Seleção Natural que nada mais é do que a sobrevivência do que melhor se adapta, em outras palavras, sobrevivência daquele que dispõe de melhores sistemas de sobrevivência em um determinado ambiente. Diante das mutações genéticas, a seleção natural selecionaria aquelas que melhor proporcionariam ao ser vivo uma possibilidade de sobreviver mais e melhor do que outro que não tem as mesmas características em um mesmo ambiente. Nesse caso, Evolução seria modificação mais seleção natural mais tempo.

\section{Implicações éticas}

Ao pensarmos nisso, poderíamos imaginar que sendo a Seleção Natural um processo natural e podendo conhecer os seus mecanismos, poderíamos assim acelerá-la. Foi assim que Francis Galton pensou ao criar a Eugenia, que é "o estudo dos agentes sob o controle social que podem melhorar ou empobrecer as qualidades raciais das futuras gerações seja física ou mentalmente". ${ }^{14}$

A Eugenia foi baseada nas ideias de Darwin e teve grande aceitação dos intelectuais na primeira metade do século XX. Assim, quando pensamos na mente maquiavélica de Hitler, devemos lembrar que ele foi influenciado por essa teoria científica. Isso não foi algo somente hitleriano. Em 1922, na Suécia, cria-se o Instituto de Biologia Racial que aprova medidas eugênicas que durarão até após a Segunda Guerra Mundial, e na Rússia stalinista, onde Hermann Mueller, descobridor de como os raios-X afetam os cromossomos, buscou o apoio de Stalin para o processo eugênico. Em nome da ciência eugênica, “foram esterilizados aproximadamente 36 mil indivíduos nos EUA, entre 1900 e $1940 " .15$

13 USP. Introdução à Evolução. Disponível em: <http://www.ib.usp.br/evosite/evo101/IIntro.shtml>. Acesso em: 18 fev. 2017.

14 GOLDIM, J. R. Eugenia. Disponível em: <https://www.ufrgs.br/bioetica/eugenia.htm>. Acesso em: 18 fev. 2017.

15 BOLSANELLO, M. A. Darwinismo social, eugenia e racismo "científico": sua repercussão na sociedade e educação brasileiras. Revista Educar, Curitiba, n. 12, p. 153-165, 1996. Disponível em: <http://www.scielo.br/pdf/er/n12/n12a14.pdf>. Acesso em: 27 fev. 2017. 
Assim conceitos científicos são utilizados na política, o que justificava as loucuras de Hitler ao matar os considerados inferiores, pois esses a natureza eliminaria, deixando assim aqueles que melhor se adaptassem. Na procura pelo "super-homem ariano", os alemães e uma boa parte da população da Europa apoiaram as disparidades do Holocausto, um dos maiores atos de crueldade de todos os tempos. Tudo em nome da ciência.

$\mathrm{Na}$ pretensa guerra entre ciência e religião, embora cientificistas digam que a religião tem atrasado o progresso da ciência, é bom informar que mentiras foram criadas para denegrir a religião, como o mito da terra plana. O historiador Jeffrey Burton Russell explica:

A mentira terra plana era munição contra os criacionistas. $\mathrm{O}$ argumento era simples e poderoso, se não elegante: "Veja como esses cristãos são estúpidos. Eles estão sempre ficando no caminho da ciência e do progresso. Essas pessoas que negam a evolução hoje são exatamente o mesmo tipo de pessoas como aqueles idiotas que durante pelo menos mil anos negaram que a terra era redonda. Você consegue ser tão estúpido?".16

É óbvio que mentiras como essas atrasaram a ciência, pois influenciaram o pensamento histórico das pessoas, que passaram a alimentar preconceitos contra determinadas instituições religiosas, tudo baseado em mentira. Se formos analisar no quesito ciência histórica, foi um atraso de século de ensino nas escolas de forma errada. $\mathrm{O}$ efeito disso ainda hoje pode ser visto nas salas de aula, onde deveria ser um lugar de conhecimento e liberdade, na verdade se torna o contrário, quando se propaga uma mentira rotulada de verdade.

Além da eugenia, outra filosofia foi baseada nas Teorias de Darwin, o Comunismo! Marx era fã de Darwin e até mesmo quis dedicar seu livro a ele. Foi o evolucionismo como teoria científica que deu o aparato para que o Marxismo fosse elevado ao status de "socialismo científico", foi um conceito evolucionista, que era biológico, aplicado a sociologia e à economia, que gerou o Marxismo, Richard Pipes diz:

O conceito marxista de evolução social surgiu sob a influência da teoria darwiniana formulada em 1859, em A origem das espécies. O livro de Darwin descrevia a emergência das espécies biológicas como devida a um processo de seleção natural que as capacitaria a sobreviver em um ambiente hostil. O processo foi dinâmico, desenvolvendo espécies de estágios inferiores para superiores, segundo regras determinadas. Essa teoria foi rapidamente adaptada por estudiosos do comportamento humano, dando origem a uma escola de 'sociologia evolucionista' que descrevia a história como uma progressão, 'por estágios', de formas inferiores para formas superiores. A

16 RUSSEL, J. B. The Myth of the Flat Earth. Disponível em: <http://www.asa3.org/ASA/topics/history/1997Russell.html>. Acesso em: 18 fev. 2017. 
influência de Darwin sobre Marx foi grande que Engels, discursando em seu funeral, disse: 'Assim como Darwin descobriu a lei do desenvolvimento da natureza orgânica, Marx descobriu a lei da história humana'.17

O comunismo foi responsável pelo maior genocídio da história humana, isso sob influência direta das implicações éticas da Teoria da Evolução.

No entanto, toda essa implicação ética não mostra que a Teoria esteja errada. Isso seria um erro lógico, não julgamos a veracidade ou falsidade de algo pelos resultados práticos de tal Teoria, mesmo o cristianismo já foi usado como pretexto para ser cruel, como é no caso das inquisições medievais, e atualmente muitas pessoas usam a Bíblia, distorcendo suas palavras para explorar a fé alheia, mas existe a possibilidade de ela estar certa? A maioria esmagadora dos cientistas acredita na Teoria da Evolução, isso também não é argumento para afirmar que a Teoria da Evolução está correta, mas se quisermos dizer que ela está errada, temos que ter argumentos que façam uma pessoa de fato desacreditar dela. Existem cientistas cristãos, como é o caso do famoso geneticista Francis Collins e do teólogo e biofísico Alister McGrath, que acreditam nessa Teoria, e isso nos leva a mais uma pergunta, que tentaremos resolver adiante.

\section{Pode um cristão ser evolucionista?}

Segundo A. H. Strong, famoso teólogo batista:

A evolução não pode fornecer evidência que afaste da natureza o desígnio. Ela pode retrocedê-lo a um ponto mais remoto da entrada, aumentando a nossa admiração na força do Criador no cumprimento dos desígnios ulteriores por processos diferentes. ${ }^{18}$

O problema está dos dois lados, de um lado temos teólogos que estão fechados a novas verdades, como criacionistas da Terra Jovem, e do outro, biólogos como Richard Dawkins, ${ }^{19}$ que querem usar a Teoria da Evolução para validar o ateísmo, extrapolando o campo da ciência e tornando-a uma filosofia universal. A. H. Strong diz:

17 PIPES, R. O comunismo. Rio de Janeiro: Objetiva/Biblioteca do Exército, 2014. p. 18.

18 WRIGHT apud STRONG, A. H. Teologia Sistemática. ed. rev. e amp. São Paulo: Hagnos, 2007. p. 150.

19 Biólogo e autor do livro Deus um Delírio, no qual defende o ateísmo. Utiliza-se da teoria da evolução para promover ateísmo. Esse tipo de estratégia tem sido adotada por alguns ateus, confundindo ciência com ateísmo, fazendo assim uma pregação ateísta disfarçada de divulgação científica. O também Dr. Francisco J. Ayala defende justamente o contrário. E defende a ideia de que "a origem das espécies e as características requintadas dos organismos tinham sido previamente explicadas como criações especiais de um Deus onisciente", referindo-se à teoria evolutiva. Para acompanhar esse debate: <https:/ /link.springer.com/article/10.1007\%2Fs40656-014-0031-0>. Acesso em: 27 fev. 2017. 
A evolução é o método de Deus. Ela se refere ao como, não ao porquê, dos fenômenos e, por isso, não inconsistente com o desígnio, porém é a sua nova é mais elevada ilustração. Como diria HENRY WARD BEECHER: 'No atacado, o desígnio é maior que no varejo.' FRANCES POWER COBBE: 'É singular o fato de que, sempre que achamos como se faz uma coisa, nossa primeira conclusão parece indicar que não foi Deus que fez'. Por que iríamos dizer: Quanto maior é a lei menor Deus? O teísta faz referências aos fenômenos como uma causa que se conhece a si mesma e sabe-se que ela está fazendo; o ateísta faz referência a eles como uma força de que nada se conhece e não se sabe o que está fazendo. ${ }^{20}$

Se a evolução das espécies for verdadeira, em hora alguma podemos descartar Deus, é um erro avaliar a Teoria da Evolução somente sob uma ótica mecânica, pois embora a Teoria da Evolução se proponha a dizer como foram feitas as coisas, isso não implica que conhecendo o processo não foi Deus que fez, pois ela apenas diz como, mas não responde o porquê das coisas. A. H. Strong explica:

A casa não requer nenhum arquiteto porque é construída por pedreiros e por carpinteiros? A lei natural sem Deus não é mais do que uma luva sem mão e tudo que se faz com a mão de Deus calçada na natureza, não é luva que faz, mas a mão. A evolução não é uma força; é um processo; não é um operador, mas um método de operação. Um livro não é escrito pelas leis de soletração e gramática, mas de acordo com tais leis. ${ }^{21}$

Portanto, é errado associar Teoria da Evolução a processos randômicos, uma coisa não implica na outra. Um dos argumentos de alguns cristãos contra a Teoria da Evolução é que ela prega que tudo foi gerado de forma natural e do acaso, isso se deve a cientistas ateístas que usam seus pressupostos metafísicos para fazer tal afirmação. Cabe aos cristãos não aceitar essa interpretação. Se a Teoria da Evolução for verdadeira, e o cristianismo for verdadeiro, ela necessariamente deve ter sido guiada, não se pode de forma alguma deixar que os pressupostos ateístas se apossem da ciência que foi criado dentro do seio da Igreja cristã.

\section{A Teoria do Design Inteligente 22}

“A teoria do design inteligente sustenta que certas características do universo e dos seres vivos são melhor explicadas por uma causa inteligente, e não por um processo

20 STRONG, 2007, p. 150. As letras em caixa alta dessa citação estão conforme foi citado no livro, o autor e o editor do livro resolveram assim colocar no material, o autor desse artigo apenas reproduziu de forma igual, também em caixa alta.

21 STRONG, 2007, p. 150.

22 Quando falo de Teoria do Design Inteligente, refiro-me ao movimento liderado por Philip Johnson, Stephen Meyer, Michael Behe e Cia. Não confundir com Designer Inteligente defendido por Lane Craig, Francis Collins e cia. 
não direcionado, como a seleção natural". ${ }^{23}$ A Teoria do Design Inteligente (TDI) não defende que todas as coisas foram criadas, e sim, que algumas coisas apresentam características de que foram criadas, logo, por consequência, o Design não implica que seja o Deus cristão, mas apenas um criador.

A TDI parte de um método indutivo, ao invés de um dedutivo. Ela não assume o Design no começo, mas ela chega à conclusão de que o projetista existe através do estudo da criação. Isso está de acordo com o método científico moderno. Os métodos usados são a complexidade irredutível, criado por Michael Behe, que seria uma característica de um sistema biológico de que seria impossível ele se formar por sucessivas e leves modificações durante o tempo, ou seja, se uma de suas partes deixasse de funcionar, o sistema inteiro colapsaria. Outro método é o da complexidade especificada, criado por William Dembski, que afirma que se um agente inteligente deixa marcas de sua inteligência, essa marca tem duas características:

1 - a coisa projetada é complexa, e

2 - ela se encaixa em dado padrão independente - usando o termo técnico, ela é especificada. ${ }^{24}$

Para Dembski, quanto maior a complexidade de algo, menor a possibilidade desse algo ter surgido por acaso, logo, a premissa 1 pode ser definida também como um evento altamente improvável de acontecer por acaso, ou seja, não basta a coisa ser complexa, nem mesmo ter uma mensagem específica, mas tem que reunir as duas condições. Os principais exemplos de complexidade irredutível e de complexidade especificada são o flagelo bacteriano, a estrutura e a informação presente do DNA e a alegada impossibilidade do surgimento natural da vida.

\section{Quando a teoria do design inteligente e a teoria da evolução são prejudiciais ao debate teológico}

Muitos têm sido os cristãos e os ateus que têm se apossado das teorias como do Design Inteligente (TDI) e da Evolução (TE) para tentar mostrar cientificamente que a vida na Terra tem um criador, ou para dizer que não tem um criador, ou seja, para comprovar suas teses teológicas. Acreditamos que possa existir um erro em relação a algumas interpretações da natureza e suas conclusões teológicas, alguns argumentos, baseados na ciência, não devem ser usados como alicerce de um arrazoado para a existência de Deus, e também para sua inexistência, simplesmente porque o argumento em questão é instável demais para tirar conclusões teológicas baseadas nele. Adiante mostraremos porque

23 DISCOVERY INSTITUTE. Center of Sicence \& Culture. Frequently Asked Questions Disponível em: <http://www.discovery.org/id/faqs/\#questionsAboutIntelligentDesign>. Acesso em: 26 fev. 2017.

24 DEMBSKI, W. A; WITT, J. Design Inteligente sem censura: um guia prático para o debate. São Paulo: Cultura Cristã, 2012. p. 55. 
devemos ser cautelosos ao usar essas duas teorias para confirmar teses teológicas e, além disso, para falar de verdades eternas, como a Bíblia pretende tratar.

Veja que se os proponentes do Design Inteligente advogam que essa teoria é de fato científica, então deverão estar abertos à total possibilidade de estarem errados, exatamente porque não se pode ter certezas absolutas em ciência, ou seja, se a complexidade irredutível for algo científico, essa poderá cair a qualquer momento e o cristão que se utilizou desse argumento para basear um argumento teológico acabará por ser envergonhado em seu discurso. É só pensar que ao invés de criar algo pronto, descobrirem como estruturas julgadas complexamente irredutíveis foram formadas passo a passo, através das leis criadas por Deus. Se um cristão usar como argumento desse tipo de "lacuna na ciência" como evidência para a existência de Deus, o ateísta terá todo motivo para alegar a não existência de Deus através da anulação desse argumento.

Agora no caso do ateísta, suponhamos que o homem consiga fabricar vida em laboratório, poderá surgir algum evolucionista como Richard Dawkins e dizer que não precisamos de Deus para mais nada, pois a vida seria um processo natural e isso foi provado, de forma que o projetista é a própria natureza. Nesse caso, o ateísta está a usar a ciência para inferir conclusões erradas, pois a verdade é que se o homem conseguir produzir uma vida, Universo, ou qualquer outro objeto, não prova nada a não ser que o homem descobriu os mecanismos pelo qual isso funciona e isso em hipótese alguma refuta a ideia de Deus, pelo contrário, a ordem ali estabelecida mostra um planejador, seria como descartar o projetista de um automóvel porque alguém descobriu como se constrói um, não faz sentido.

Nos dois casos citados acima, nem o cristão tampouco o ateísta estão certos, pois estão discutindo sobre a base errada da questão, são os pressupostos cristãos que devem ser usados na ciência, como a ordem existente e a necessidade de um legislador e organizador a fim de tornar o Universo um lugar inteligível para o estudo e compreensão da mente humana, não as possibilidades ou impossibilidades momentâneas dentro da ciência que devem ser o argumento que corrobore para complementar os estudos teológicos, pois o que é impossível hoje, amanhã poderá ser possível. Portanto, esse argumento é muito instável.

Deve-se ter toda cautela nesse tipo de debate, nos exemplos citados nem os ateus nem os cristãos estão certos, pois o argumento para a existência de Deus e da veracidade da Bíblia quando se trata de investigação do mundo, é a ordem, são as leis da natureza. Se existe uma ordem no universo, basta o homem descobrir essa ordem, essa lei, o mecanismo de como funciona, que obedece a uma lógica e tudo estará desvendado, seja o surgimento da vida ou de qualquer outro objeto. A grandeza do criador será manifestada quando a descoberta mostrar o tamanho da engenhosidade que precisa para construir algo tão maravilhoso como a vida, universo etc. Esse é um dos aspectos em que a teologia deve 
ser útil à ciência. Um ateísta não poderá usar a ciência para descartar a existência de Deus, pois sequer Deus é objeto de estudo da ciência e a ciência por si é muito limitada, nem o cristão usá-la como fonte autoritativa para demonstrar a existência de Deus.

\section{A ciência e teologia: como o cristão deve relacioná-las}

Citaremos dois exemplos para exemplificar como relacionar esses modos de interpretação do mundo um com o outro. O primeiro exemplo é a o caso citado no livro de Josué em que está escrito que o Sol parou (Js 10.12-13). ${ }^{25}$ As descobertas científicas mostram de forma irrefutável que é a Terra que gira em torno do Sol, não o contrário. Assim, podemos dizer que a ciência nos ajuda a entender melhor o texto e até abrir "jurisprudência" para novas possibilidades exegéticas, pois ali fica claro que está registrado a visão do homem que viu, e não uma verdade científica, assim devemos ser atenciosos ao discernir quando está registrado a visão de um homem ou a sua crença e não uma verdade científica. Augustus Nicodemus diz que "a Bíblia não é um livro de ciências". ${ }^{26}$ Então, defendemos aqui que a Bíblia nunca tem como objetivo revelar uma verdade científica, mas sim verdades teológicas essenciais para a salvação da alma do homem, algo que a ciência jamais poderá fazer.

Por outro lado, vimos mais acima, como algumas teorias científicas podem ser usadas para cometer os piores tipos de crimes contra a humanidade. Os pressupostos cristãos que incluem amor ao próximo, altruísmo, igualdade de direitos entre as pessoas, devem guiar as conclusões científicas para que possa se manter uma ética que a ciência por si só não pode oferecer, algo como a Eugenia jamais pode ser uma conclusão de um cientista cristão, pois fere toda a moral cristã.

\section{Considerações finais}

Não existe guerra entre ciência e religião cristã. Essa aparente guerra foi criada por pessoas tendenciosas que queriam impor sua ideologia ao invés de promover uma busca sincera pela verdade. A ciência moderna surgiu dentro o seio da igreja cristã, nem católicos nem protestantes jamais se pronunciaram contra a investigação científica. Casos isolados e polêmicos devem ser estudados a fundo e seria motivo de explanação em outro artigo.

As Teorias da Evolução e Design Inteligente travam uma luta sobre as origens. No entanto, as disputas científicas não têm o poder de abalar nossas convicções teológicas,

25 Então Josué falou ao Senhor, no dia em que o Senhor deu os amorreus nas mãos dos filhos de Israel, e disse na presença dos israelitas: Sol, detém-te em Gibeom, e tu, lua, no vale de Ajalom. E o sol se deteve, e a lua parou, até que o povo se vingou de seus inimigos. Isto não está escrito no livro de Jasher? O sol, pois, se deteve no meio do céu, e não se apressou a pôr-se, quase um dia inteiro (Josué 10.12-13).

26 Presente no vídeo no

<https:/ / www.youtube.com/watch?v=XRllSeFCjf0>. Acesso em: 26 fev. 2017. 
pois a crença em Deus e na Bíblia não devem estar condicionadas a verdades científicas, porque as verdades de Deus são eternas, e as verdades científicas são passageiras. Aqueles que usam a TE para promover o ateísmo e usam a TDI para promover o teísmo, sobretudo o cristão, erram ao fazer isso, pois não se pode concluir através da TE que Deus não existe, isso vai além de sua competência, e não se promover verdades teológicas através da TDI, porque as bases são instáveis.

A ciência pode ajudar o cristão a melhor interpretar a Bíblia, e também a confirmar alguns fatos bíblicos através da arqueologia, ou mesmo através de recursos multimídias que ajudaria o cristão a maximizar seus estudos ou auxiliá-lo na pregação do evangelho. Concluímos que a ciência deve ser serva do cristão, não o contrário. O cristão deve usar os pressupostos éticos do cristianismo na ciência, um cientista cristão jamais deve aceitar implicações éticas que firam a moral cristã. Assim, garantiremos que não promoveremos outros genocídios, ou criaremos ideologias tenebrosas que ganham status entre a comunidade sob um pretexto de serem científicas como o comunismo e a eugenia. Se há um lugar onde a ciência e a teologia devem se encontrar, deve ser no promover o bem para a humanidade, a ciência cuida do corpo, enquanto a teologia cuida da alma.

\section{Referências}

BOLSANELLO, M. A. Darwinismo social, eugenia e racismo "científico": sua repercussão na sociedade e educação brasileiras. Revista Educar, Curitiba, n. 12, p. 153-165, 1996. Disponível em: <http://www.scielo.br/pdf/er/n12/n12a14.pdf>. Acesso em: 27 fev. 2017.

CAIRNS, E. E. O cristianismo através dos séculos: uma história da igreja cristã. São Paulo: Vida Nova, 1995.

DEMBSKI, W. A; WITT, J. Design Inteligente sem censura: um guia prático para o debate. São Paulo: Cultura Cristã, 2012.

DILLEY, S. Charles Darwin's use of theology in the Origin of Species. British Journal for the History of Science, v. 45, mar. 2012. Disponível em: <https:/ / www.ncbi.nlm.nih.gov/pubmed/22702030>. Acesso em: 20 fev. 2017.

DISCOVERY INSTITUTE. Center of Sicence \& Culture. Frequently Asked Questions Disponível em: <http://www.discovery.org/id/faqs/\#questionsAboutIntelligentDesign>. Acesso em: 26 fev. 2017.

GOLDIM, J. R. Eugenia. Disponível em: <https://www.ufrgs.br/bioetica/eugenia.htm>. Acesso em: 18 fev. 2017.

JEYNES, C. Science and Creation: an abridgement of the book by Stanley Jaki. Abril 2002. Disponível em: <https://www.surrey.ac.uk/ati/ibc/files/Science\&Creation.pdf>. Acesso em: 14 fev. 2017. 
PIPES, R. O comunismo. Rio de Janeiro: Objetiva/Biblioteca do Exército, 2014.

PORT JR, W. A relação entre João Calvino e o desenvolvimento das ciências modernas. Revista de Teologia Brasileira, 2013. Disponível em: <http:/ / www.teologiabrasileira.com.br/teologiadet.asp?codigo=350>. Acesso em: 18 fev. 2017.

RAMSEY, R. B. Integridad intelectual: el desarrollo de una cosmovisión cristiana. [s.l.]: Clie, [s.d.].

RUSSEL, J. B. The Myth of the Flat Earth. Disponivel em: <http://www.asa3.org/ ASA/topics/history/1997Russell.html>. Acesso em: 18 fev. 2017.

STRONG, A. H. Teologia Sistemática. ed. rev. e amp. São Paulo: Hagnos, 2007.

USP. Introdução <http://www.ib.usp.br/evosite/evo101/IIntro.shtml>. Acesso em: 18 fev. 2017. 